\title{
Vibrational spectroscopic studies of L,D-alternating valine peptides
}

\author{
Vaman M. Naik \\ Department of Natural Sciences, University of Michigan-Dearborn, Dearborn, MI 48128 (USA)
}

(Received 31st May 1991)

\begin{abstract}
Raman and infrared spectra of Boc-(L-Val-D-Val) ${ }_{n}-\mathrm{OMe}\left[(\mathrm{LD}-\mathrm{Val})_{n}\right]$, with $n=4,6$ and 8, were obtained in crystalline and solution states. Based on predictions from normal-mode calculations of a number of relevant singleand double-stranded $\beta$-helix conformations, structures were assigned for the three oligopeptides under the abovementioned conditions. In the crystalline state, all three oligopeptides have a double-stranded $\uparrow \downarrow \beta^{5.6}$ structure. In cyclohexane and in chloroform, the $\uparrow \downarrow \beta^{5.6}$ structure predominates for (LD-Val) $)_{4}$. In chloroform the (LD-Val) 6 has a $\beta^{4.4}$ structure. (LD-Val) $)_{8}$ in cyclohexane and in chloroform exists predominantly in a $\uparrow \downarrow \beta^{5.6}$ structure together with some $\beta^{4.4}$.
\end{abstract}

Keywords: Infrared spectrometry; Raman spectrometry; Peptides; Valine

During the past few years, peptides and polypeptides with a regular sequence of enantiomeric residues ( $L$ and $D$ ) along the chain have received considerable attention [1-11]. This is mainly due to their analogy with gramicidin A, a naturally occuring linear pentadecapeptide that forms an ion-conducting channel across natural and synthetic lipid bilayer membranes (for a review, see [12]). These L,D-alternating oligopeptides can assume, in addition to the well known structures such as an $\alpha$-helical structure, a wide variety of conformations including single $\left(\beta^{n}\right)$ and double-stranded helices. With double-stranded helices, the conformations could be of parallel $\left(\uparrow \uparrow \beta^{n}\right)$ or antiparallel $\left(\uparrow \downarrow \beta^{n}\right)$ type. Here, the superscript $n$ refers to the total number of residues per turn of the helix. Two octapeptides, Boc-(L-Val-D-Val) ${ }_{4}-\mathrm{OMe}$ and Boc-(L-Phe-DPhe) ${ }_{4}$-OMe, are shown to exist in a doublestranded antiparallel $\beta$-structure of the type $\uparrow \downarrow \beta^{5.6}$, by single-crystal x-ray diffraction studies
[2,3]. The valine octapeptide is shown to be a left-handed whereas the phenylalanine octapeptide is a right-handed helix.

Vibrational spectroscopy (infrared and Raman), through the use of normal-mode analysis to predict the vibrational frequencies expected for a given conformation, can be used to obtain information on the secondary structure of polypeptide molecules [13]. Naik and Krimm [14] have calculated normal modes for several single- $\left(\beta^{4.4}\right.$ and $\left.\beta^{6.3}\right)$ and double-helical $\left(\uparrow \downarrow \beta^{5.6}, \uparrow \downarrow \beta^{7.2}\right.$, $\uparrow \uparrow \beta^{5.6}$ and $\uparrow \uparrow \beta^{7.2}$ ) structures and used the results to predict the conformation of gramicidin $A$ in the ion-free crystalline state, ion-bound crystalline state, solution and in synthetic membranes $[15,16]$. The structures predicted based on vibrational spectroscopy and normal-mode analysis were confirmed later by single-crystal $x$-ray analyses [17-19]. In the crystalline state, the uncomplexed gramicidin $\mathbf{A}$ has a double-stranded $\uparrow \downarrow \beta^{5.6}$ structure [19], whereas a cesium ion com- 


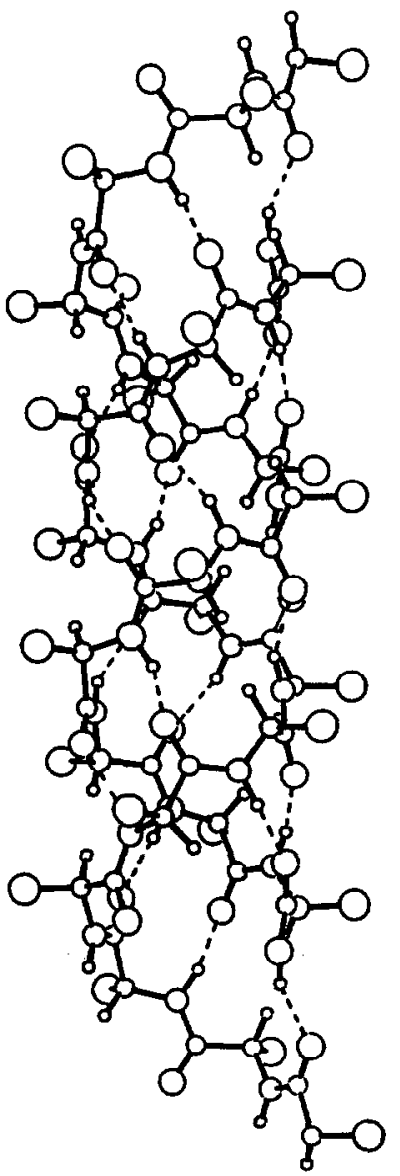

Fig. 1. ORTEP drawing of $\uparrow \downarrow \beta^{5.6}$ structure.

plex adopts a $\uparrow \downarrow \beta^{6.4}$ structure [18]. In lipid vesicles, i.e., in the conducting state, gramidicin $A$ is found in a single-stranded $\beta^{6.3}$ helix [14].

In this work, a series of three valine oligopeptides, namely Boc-(L-Val-D-Val) $n$-OMe, with $n=$ 4, 6 and 8, were studied; Boc-(L-Val-D-Val) ${ }_{n}$-OMe is subsequently referred to as (LD-Val) $n_{n}$. The structure of ( $\mathrm{LD}-\mathrm{Val})_{4}$ is known to be in the left-handed $\uparrow \downarrow \beta^{5.6}$ which is stabilized by fourteen $\mathrm{NH} \cdots$ OC hydrogen bonds. The structure can be regarded as a cylinder with an inner diameter of 5.1 $\AA$ [2]. An ORTEP drawing of the $\uparrow \downarrow \beta^{5.6}$-helix is given in Fig. 1. $A \uparrow \downarrow \beta^{5.6}$ structure with fifteen amino acid residues (in each chain) would have a maximum length of $31.5 \AA$ [4], which is long enough to span the lipid bilayer. The structures of (LD-Val) 6 and (LD-Val) 8 have not yet been determined by $\mathrm{x}$-ray analysis. Infrared (IR) and Raman spectra of all of the above oligopeptides are presented and the possible structures in the crystalline and solution states are discussed.

\section{EXPERIMENTAL}

The oligopeptides (LD-Val) $n$ with $n=4,6$ and 8 were synthesized by and kindly provided by $\mathrm{Dr}$. G.P. Lorenzi. (LD-Val) 4 and (LD-Val) 6 were deuterated with $\mathrm{CHCl}_{3}$-EtOAc solution floating over $\mathrm{D}_{2} \mathrm{O}$. Ethyl acetate contains $2 \%$ of $\mathrm{H}_{2} \mathrm{O}$, and the immiscible peptide $\mathrm{CHCl}_{3}-\mathrm{EtOAc}$ solution floating over $\mathrm{D}_{2} \mathrm{O}$ was stirred for about 2 days. The small amount of $\mathrm{H}_{2} \mathrm{O}$ present in EtOAc was exchanged to $\mathrm{D}_{2} \mathrm{O}$, and thus leading to the deuteration of the octapeptide. (LD-Val) 8 was deuterated from a solution of $\mathrm{CHCl}_{3}-\mathrm{MeOD}$. The molecules were not completely deuterated. However, the deuteration achieved was sufficient to identify the deuteration-sensitive modes.

IR spectra of solid samples were recorded in $\mathrm{KBr}$ disks using a Perkin-Elmer Model 180 dispersive spectrometer with ca. $2 \mathrm{~cm}^{-1}$ resolution at $1800 \mathrm{~cm}^{-1}$ and a Bomem DA/3 Fourier transform IR (FT-IR) spectrometer equipped with an HgCdTe detector. The FT-IR spectra were recorded with a resolution of $1 \mathrm{~cm}^{-1}$. The IR spectra of samples in solution were recorded using a $\mathrm{CaF}_{2}$ cell with a peptide concentration of ca. $0.5 \%$. The solution IR spectra were recorded using the dispersive spectrometer mentioned above.

Raman spectra were recorded, using a Spex 1403 spectrometer equipped with a double monochromator, with an excitation line of 514.5 $\mathrm{nm}$ from a Spectra-Physics Model 165 argon ion laser. For solid samples, an incident laser power of ca. $150 \mathrm{~mW}$ was focused at the samples, sealed in glass capillaries. The spectral band pass was ca. $2 \mathrm{~cm}^{-1}$ at $514.5 \mathrm{~nm}$ and the step resolution used was $1 \mathrm{~cm}^{-1}$ in all the spectra. For solution samples, the incident laser power of ca. $200 \mathrm{~mW}$ was focused at the capillaries containing the sample solutions. The spectral band pass was ca. 3 $\mathrm{cm}^{-1}$ at $514.5 \mathrm{~nm}$. Because of the low concentra- 


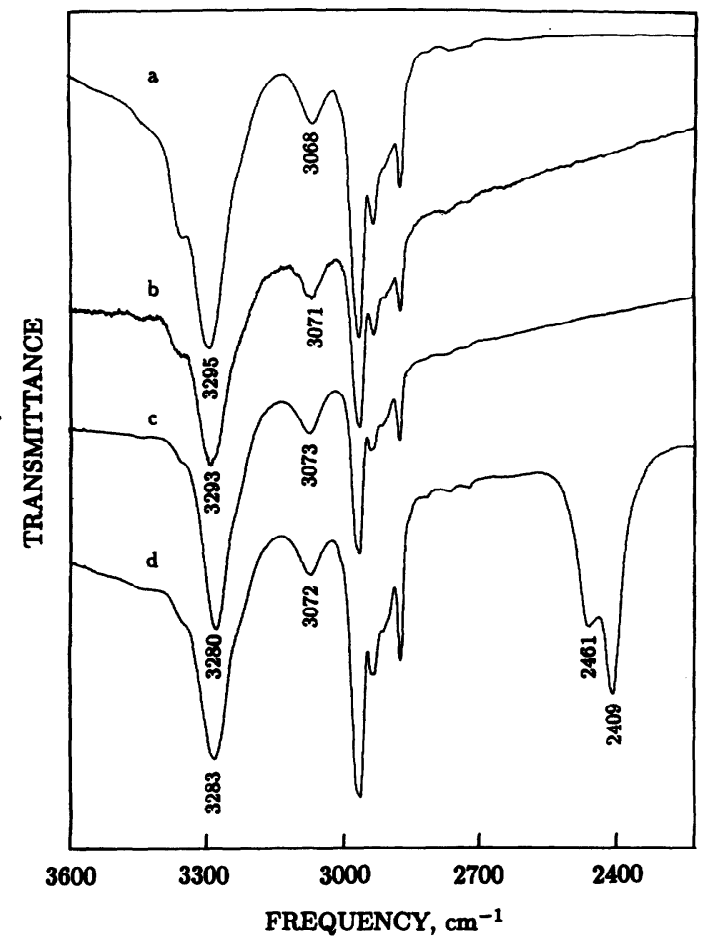

Fig. 2. IR spectra in the $3600-2200 \mathrm{~cm}^{-1}$ region of (a) $(\mathrm{LD}-\mathrm{Val})_{4}$, (b) (LD-Val) 6 , (c) (LD-Val) 8 and (d) $N$-deuterated $(\mathrm{LD}-\mathrm{Val})_{8}$.

tion of the samples, the spectra were averaged over a large number of scans (ca. 50) to obtain a better signal-to-noise ratio.

\section{RESULTS}

IR spectra of (LD-Val) $n$ with $n=4,6$ and 8 and one of their $\mathrm{N}$-deuterated derivatives are shown in Figs. 2-5. The Raman spectra of these molecules are given in Figs. 6 and 7. Figure 8 shows the IR amide I frequencies of (LD-Val) 6 and (LD-Val) $)_{8}$ in $\mathrm{CHCl}_{3}$ and Fig. 9 shows the Raman amide I frequencies of all the three valine oligopeptides in $\mathrm{CHCl}_{3}$. Table 1 lists the amide A, B, I, II, III and V frequencies of all three oligopeptides in the crystalline state. Table 2 lists the IR and Raman amide $A$ and amide $I$ frequencies for the three oligopeptides in solution. Table 3 lists the calculated amide I, II, III and V frequencies of the $\uparrow \downarrow \beta^{5.6}$ and $\uparrow \downarrow \beta^{7.2}$ structures
[14]. The calculated amide frequencies for the $\beta^{4.4}$ and $\beta^{6.3}$ structures are given in Table 4 [14].

\section{DISCUSSION}

Conformation of oligovalines in crystalline state

The vibrations due to $\mathrm{CH}$ and $\mathrm{CH}_{3}$ groups of valine side-chains are very localized and are well characterized [20-22]. The $\mathrm{CH}_{3}$ group vibrations arising from the oxymethyl and $t$-Boc blocking group, and other end-group frequencies such as the $\mathrm{C}-\mathrm{O}$ stretching mode, are easily assignable based on the earlier work on ethyl acetate and its $N$-deuterated derivatives [23]. Here mainly the conformationally sensitive modes, namely amide A, B, I, II, III and V modes, will be discussed.

In the conformationally sensitive regions, all three oligopeptides exhibit similar spectra. Amide $A$ and $B$ bands arise from Fermi resonance be-

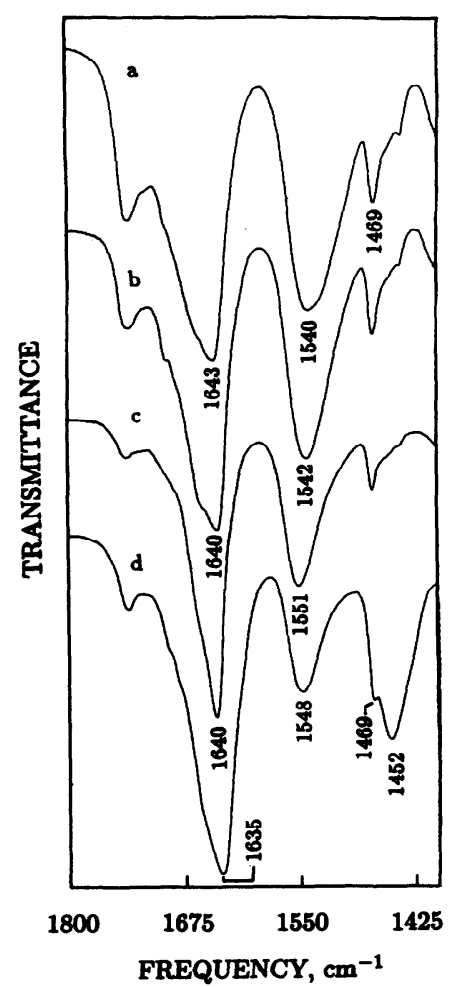

Fig. 3. IR spectra in the $1800-1400 \mathrm{~cm}^{-1}$ region of (a) $(\mathrm{LD}-\mathrm{Val})_{4}$, (b) $(\mathrm{LD}-\mathrm{Val})_{6}$, (c) (LD-Val) 8 and (d) $N$-deuterated (LD-Val) 6 . 
tween the NH stretching frequency and the first overtone of the amide II (consisting mainly of $\mathrm{NH}$ in-plane motion) frequency. Both of these frequencies are sensitive to the backbone conformation of the polypeptide and usually amide $A$ occurs at ca. $3300 \mathrm{~cm}^{-1}$ and amide B at ca. 3100 $\mathrm{cm}^{-1}$.

The amide $A$ band observed at $3295 \mathrm{~cm}^{-1}$ in both the IR and Raman (R) spectra for (LD-Val) shifts down to $3293 \mathrm{~cm}^{-1}$ (IR) and to $3290 \mathrm{~cm}^{-1}$ (R) in (LD-Val) 6 , and finally to $3280 \mathrm{~cm}^{-1}$ (IR) and to $3267 \mathrm{~cm}^{-1}(\mathrm{R})$ in $(\mathrm{LD}-\mathrm{Val})_{8}$. This downward shift of the amide $A$ frequency on going from the octapeptide to the hexadecapeptide indicates that the hydrogen bonds in the latter peptide are stronger than those in the former. The amide $B$ mode is observed in the IR spectrum at $3068 \mathrm{~cm}^{-1}$ in (LD-Val) $)_{4}$, at $3071 \mathrm{~cm}^{-1}$ in (LD-Val) ${ }_{6}$ and at $3073 \mathrm{~cm}^{-1}$ in (LD-Val) 8 . The amide $B$ frequency is very weak in the Raman spectrum and frequently is not detectable.

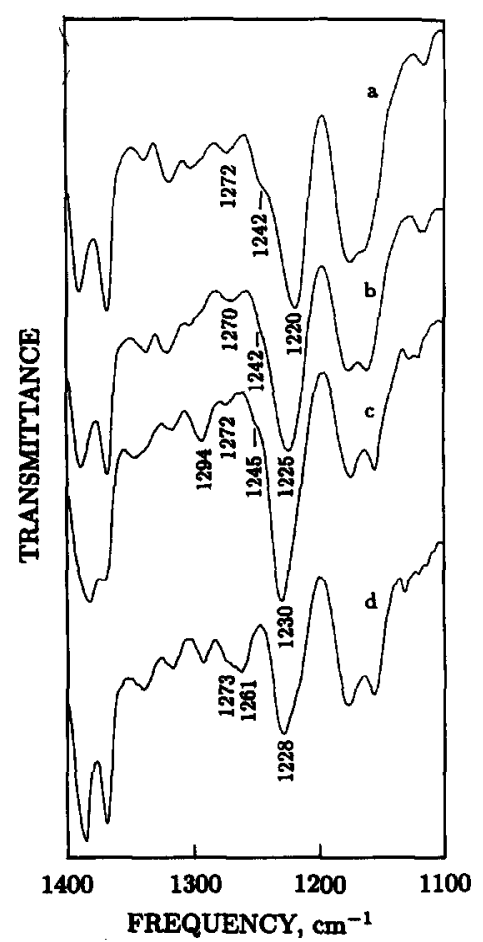

Fig. 4. IR spectra in the $1400-1100 \mathrm{~cm}^{-1}$ of (a) (LD-Val) 4 , (b) $(\mathrm{LD}-\mathrm{Val})_{6},(\mathrm{c})(\mathrm{LD}-\mathrm{Val})_{8}$ and (d) $N$-deuterated (LD-Val) ${ }_{8}$.

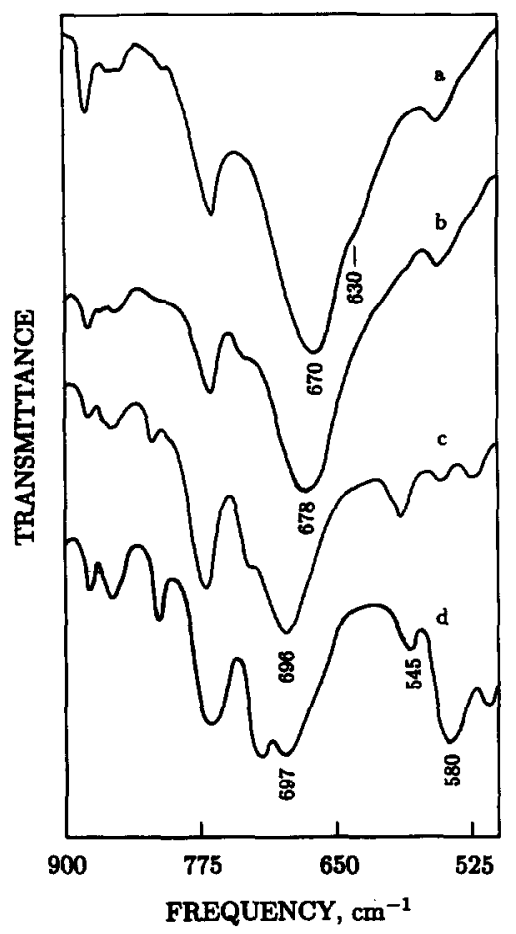

Fig. 5. IR spectra in the $900-500 \mathrm{~cm}^{-1}$ region of (a) (LD-Val) (b) (LD-Val) 6 , (c) (LD-Val) 8 and (d) $N$-deuterated (LD-Val) 8 .

The amide I modes essentially consist of $\mathrm{CO}$ stretching. The Raman amide I band of ( $\mathrm{LD}-\mathrm{Val})_{4}$ has more structure compared with the other two peptides (see Fig. 6). The strongest Raman amide $I$ band is observed at $1678 \mathrm{~cm}^{-1}$ for (LD-Val) $)_{4}$, at $1676 \mathrm{~cm}^{-1}$ for (LD-Val) 6 and at $1672 \mathrm{~cm}^{-1}$ for (LD-Val) $)_{8}$. In (LD-Val) $)_{4}$ the shoulder observed at ca. $1665 \mathrm{~cm}^{-1}$ in the Raman spectrum becomes a well resolved band at low temperature $(77 \mathrm{~K})$. Two more shoulders, at ca. $1693 \mathrm{~cm}^{-1}$ and ca. $1650 \mathrm{~cm}^{-1}$, are also visible at this temperature (spectrum not shown). In the IR spectrum, the amide I modes for these peptides are observed at ca. $1643 \mathrm{~cm}^{-1}$ for (LD-Val) 4 and at $1640 \mathrm{~cm}^{-1}$ for (LD-Val $_{6}$ and (LD-Val) $)_{8}$. All three peptides show a shoulder near $1685 \mathrm{~cm}^{-1}$ in the IR spectrum, a characteristic of an antiparallel $\beta$-sheet structure. These small differences observed in the strong amide I frequencies are attributable to the different chain lengths in these three peptides. (LD$\mathrm{Val}_{8}$, being the longest, is expected to form a more regular structure than the shorter oligopeptides. 


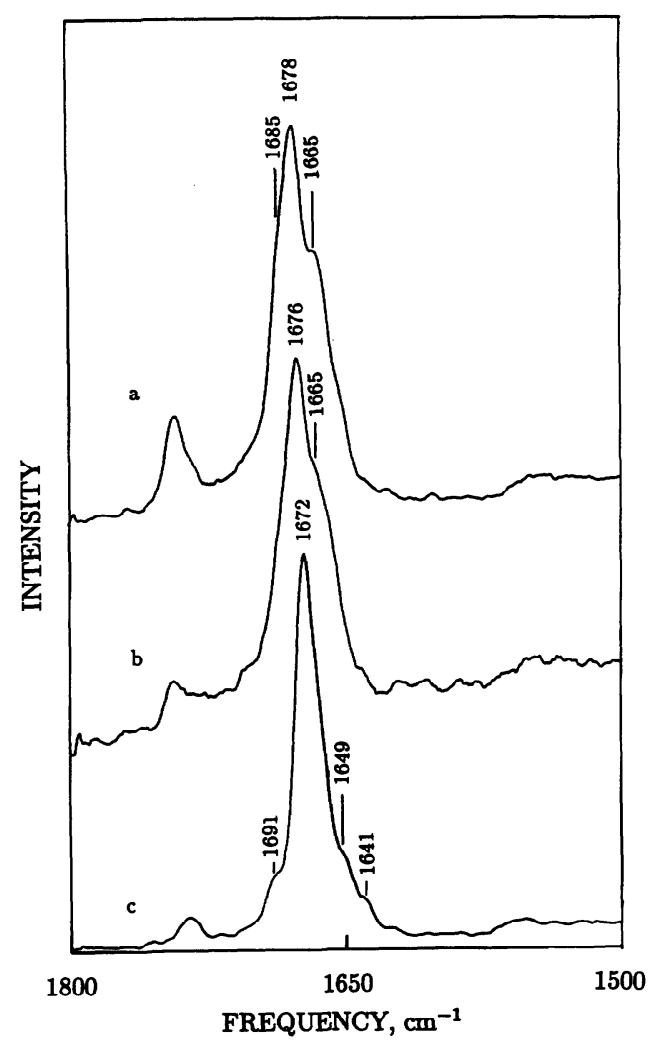

Fig. 6. Raman spectra in the $1800-1500 \mathrm{~cm}^{-1}$ region of (a) $(\mathrm{LD}-\mathrm{Val})_{4},(\mathrm{~b})(\mathrm{LD}-\mathrm{Val})_{6}$ and (c) (LD-Val) 8 .

The calculations of the normal modes of vibrations of the infinite double helices [14] predict a strong (intense) parallel-polarized (parallel to the helix axis) amide I mode in $\uparrow \downarrow \beta^{5.6}$ at $1636 \mathrm{~cm}^{-1}$ (see Table 3 ). The corresponding calculated mode in $\uparrow \downarrow \beta^{7.2}$ is at $1632 \mathrm{~cm}^{-1}$. The strongest IR amide $\mathrm{I}$ mode is expected to be an $A$ symmetry species mode and parallel-polarized. The calculated frequency of $1636 \mathrm{~cm}^{-1}$ is close to those observed for ( $\mathrm{LD}-\mathrm{Val})_{6}$ and $(\mathrm{LD}-\mathrm{Val})_{8}$. The strong IR amide I mode observed in ( $\mathrm{LD}-\mathrm{Val})_{4}$ is $7 \mathrm{~cm}^{-1}$ higher than that predicted for the $\uparrow \downarrow \beta^{5.6}$ structure. The shorter length of ( $\mathrm{LD}-\mathrm{Val})_{4}$ compared with the other two peptides can account for this observed difference. As the calculations [14] were done on infinite chains, better agreement is expected with predicted frequencies in longer chains. The lowest amide I mode calculated in $\uparrow \downarrow \beta^{5.6}$ matches very well the strongest observed

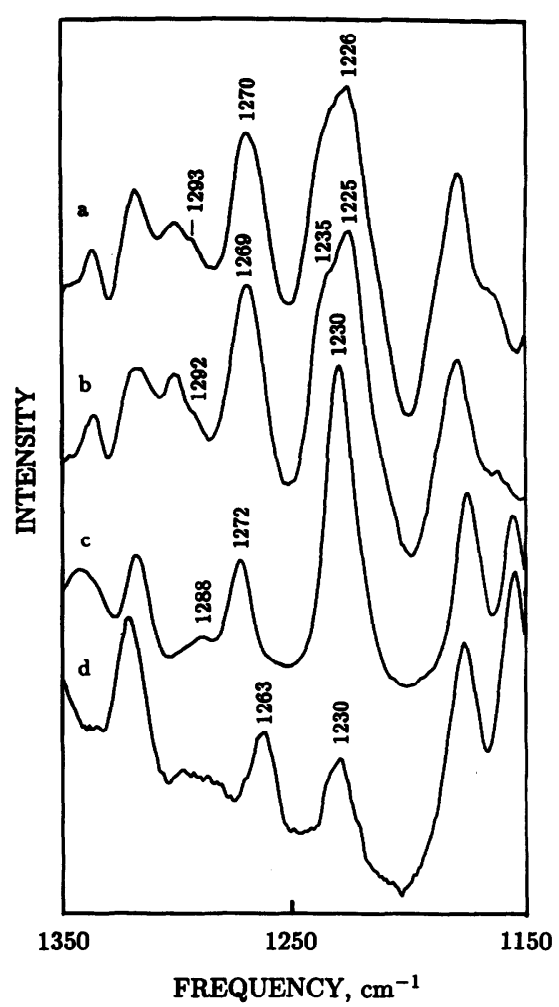

Fig. 7. Raman spectra in the $1350-1150 \mathrm{~cm}^{-1}$ of (a) (LD-Val) (b) $(\mathrm{LD}-\mathrm{Val})_{6}$, (c) (LD-Val) $)_{8}$ and (d) $N$-deuterated (LD-Val) 8 .

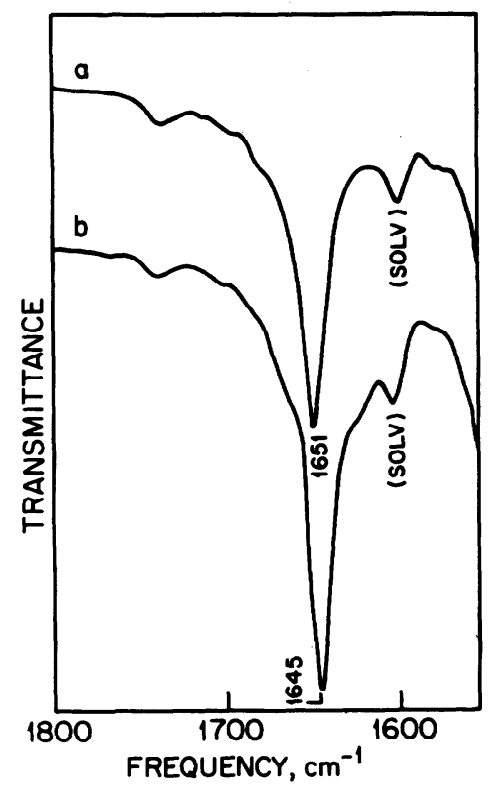

Fig. 8. IR spectra in the $1800-1500 \mathrm{~cm}^{-1}$ region of (a) (LD-Val) 6 and (b) (LD-Val) 8 in chloroform. 
TABLE 1

Observed amide frequencies $\left(\mathrm{cm}^{-1}\right)$ of (LD-Val) $)_{n}$ in the crystalline state

\begin{tabular}{|c|c|c|c|c|c|c|}
\hline \multirow[t]{2}{*}{ Mode } & \multicolumn{2}{|l|}{$(\mathrm{LD}-\mathrm{Val})_{4}$} & \multicolumn{2}{|l|}{$(\mathrm{LD}-\mathrm{Val})_{6}$} & \multicolumn{2}{|c|}{$(L D-V a l)_{8}$} \\
\hline & Raman & IR & Raman & IR & Raman & IR \\
\hline Amide A & $3295 \mathrm{w}$ & 3295 vs & $3290 \mathrm{w}$ & 3293 vs & $3267 w$ & 3280 vs \\
\hline Amide B & & $3068 \mathrm{w}$ & & $3071 \mathrm{w}$ & & $3073 w$ \\
\hline Amide I & $\begin{array}{l}1685 \mathrm{sh} \\
1678 \mathrm{~s} \\
1665 \mathrm{sh} \\
1652 \mathrm{sh}\end{array}$ & $\begin{array}{l}1685 \text { sh } \\
1660 \text { sh } \\
1643 \text { vs }\end{array}$ & $\begin{array}{l}1676 \mathrm{~s} \\
1665 \mathrm{sh} \\
1654 \mathrm{sh}\end{array}$ & $\begin{array}{l}1654 \text { sh } \\
1640 \text { vs }\end{array}$ & $\begin{array}{l}1691 \text { sh } \\
1672 \text { vs } \\
1649 \text { sh } \\
1641 \text { sh }\end{array}$ & $\begin{array}{l}1681 \mathrm{sh} \\
1652 \mathrm{sh} \\
1640 \mathrm{vs}\end{array}$ \\
\hline Amide II & $1541 \mathrm{vw}$ & $1540 \mathrm{~s}$ & $1542 \mathrm{vw}$ & $1542 \mathrm{~s}$ & $1551 \mathrm{vw}$ & $1551 \mathrm{~s}$ \\
\hline Amide III & $\begin{array}{l}1270 \mathrm{~m} \\
1236 \mathrm{sh} \\
1226 \mathrm{~s}\end{array}$ & $\begin{array}{l}1272 \mathrm{ww} \\
1242 \mathrm{sh} \\
1220 \mathrm{~m}\end{array}$ & $\begin{array}{l}1292 \mathrm{sh} \\
1269 \mathrm{~m} \\
1235 \mathrm{sh} \\
1225 \mathrm{~s}\end{array}$ & $\begin{array}{l}1270 \mathrm{w} \\
1242 \mathrm{sh} \\
1225 \mathrm{~m}\end{array}$ & $\begin{array}{l}1288 \mathrm{w} \\
1272 \mathrm{~m} \\
1230 \mathrm{~s}\end{array}$ & $\begin{array}{l}1294 \mathrm{vw} \\
1272 \mathrm{w} \\
1245 \mathrm{sh} \\
1230 \mathrm{~m}\end{array}$ \\
\hline Amide V & $\begin{array}{l}699 \mathrm{vw} \\
670 \mathrm{vw} \\
627 \mathrm{vw}\end{array}$ & $\begin{array}{l}670 \mathrm{~m} \\
630 \mathrm{sh}\end{array}$ & $\begin{array}{l}651 \mathrm{sh} \\
636 \mathrm{w}\end{array}$ & $\begin{array}{l}678 \mathrm{~m} \\
630 \mathrm{sh}\end{array}$ & $\begin{array}{l}694 \mathrm{w} \\
670 \mathrm{vw}\end{array}$ & $696 \mathrm{~m}$ \\
\hline
\end{tabular}

$\mathrm{a} s=$ Strong, $\mathrm{m}=$ medium, $\mathrm{v}=$ very, $\mathrm{w}=$ weak and $\mathrm{sh}=$ shoulder.

IR mode at $1640 \mathrm{~cm}^{-1}$ in (LD-Val) $)_{6}$ and (LD-Val) $)_{8}$. The strong Raman amide I mode observed at $1672 \mathrm{~cm}^{-1}$ in these peptides is well reproduced by $\uparrow \downarrow \beta^{5.6}$ and $\uparrow \downarrow \beta^{7.2}$ structures. Hence the calculated frequencies in the amide I region slightly favor the $\uparrow \downarrow \beta^{5.6}$ over the $\uparrow \downarrow \beta^{7.2}$ structure for $(\mathrm{LD}-\mathrm{Val})_{6}$ and $(\mathrm{LD}-\mathrm{Val})_{8}$.

The amide II mode (consisting of mainly $\mathrm{NH}$ in-plane motion and $\mathrm{CN}$ stretching) is intrinsically weak in the Raman spectrum and is not observed most of the time. It is observed in the IR spectrum usually as a broad, medium strong band at ca. $1550 \mathrm{~cm}^{-1}$. The observed amide II frequencies (see Table 1) are consistent with the predicted frequencies for the $\uparrow \downarrow \beta^{5.6}$ structure (1553-1541 $\mathrm{cm}^{-1}$ ). However, it should be pointed out that the amide II frequencies are usually not very helpful in discriminating between $\uparrow \downarrow \beta^{5.6}$ and $\uparrow \downarrow \beta^{7.2}$ structures $[14,16]$. Reliable intensity calculations will be very useful in this regard.

TABLE 2

Observed amide $A$ and $I$ frequencies $\left(\mathrm{cm}^{-1}\right)$ of $(\mathrm{LD}-\mathrm{Val})_{n}$ in solution

\begin{tabular}{|c|c|c|c|c|c|c|}
\hline \multirow[t]{2}{*}{ Mode } & \multicolumn{2}{|l|}{$(\mathrm{LD}-\mathrm{Val})_{4}$} & \multicolumn{2}{|l|}{$(\mathrm{LD}-\mathrm{Val})_{6}$} & \multicolumn{2}{|l|}{$(\mathrm{LD}-\mathrm{Val})_{8}$} \\
\hline & $\overline{\text { Raman a }}$ & $\mathrm{IR}^{\mathrm{b}}$ & Raman & IR & Raman " & IR ${ }^{a}$ \\
\hline Amide A & & $3295 \mathrm{~s}$ & & $3290 \mathrm{~s}$ & & $3280 \mathrm{~s}$ \\
\hline Amide I & $\begin{array}{l}1695 \mathrm{sh} \\
1675 \mathrm{vs}\end{array}$ & $\begin{array}{l}1691 \mathrm{sh} \\
1670 \mathrm{sh}\end{array}$ & $\begin{array}{l}1689 \mathrm{sh} \\
1672 \mathrm{vs} \\
1655 \mathrm{sh}\end{array}$ & $1680 \mathrm{sh}$ & $\begin{array}{l}1684 \text { sh } \\
1672 \text { vs }\end{array}$ & \\
\hline & $1644 w$ & 1654 vs & $1642 \mathrm{sh}$ & 1651 vs & & 1645 vs \\
\hline
\end{tabular}

In chloroform solution. ${ }^{\mathrm{b}}$ In cyclohexane solution; from [24]. 
In the amide III (generally consisting of $\mathrm{NH}$ in-plane motion and $\mathrm{CN}$ stretching) region, there are four bands in the IR spectrum, at 1294, 1272, 1245 and $1230 \mathrm{~cm}^{-1}$, in (LD-Val) 8 which lose intensity on $\mathrm{N}$-deuteration. In the IR spectra the loss of intensity in the $1272 \mathrm{~cm}^{-1}$ band is not clearly seen as some other higher frequency band moves into that region after $\mathrm{N}$-deuteration. In the Raman spectrum there are three observed amide III bands, at 1288, 1272 and $1230 \mathrm{~cm}^{-1}$. For the $\uparrow \downarrow \beta^{5.6}$ structure, modes with NH inplane contributions are calculated [14] at 1288, $1284,1267,1265$ and $1240-1236 \mathrm{~cm}^{-1}$. The observed frequencies for the three oligopeptide are in agreement with the calculated frequencies for the $\uparrow \downarrow \beta^{5.6}$ structure. The $\uparrow \downarrow \beta^{7.2}$ structure does not predict very well the lowest observed amide II band at $1230 \mathrm{~cm}^{-1}$ or the higher frequency at $1288 \mathrm{~cm}^{-1}$.

Amide $\mathrm{V}$ frequencies (consisting of $\mathrm{CN}$ torsional and NH out-of-plane motions) are weak in

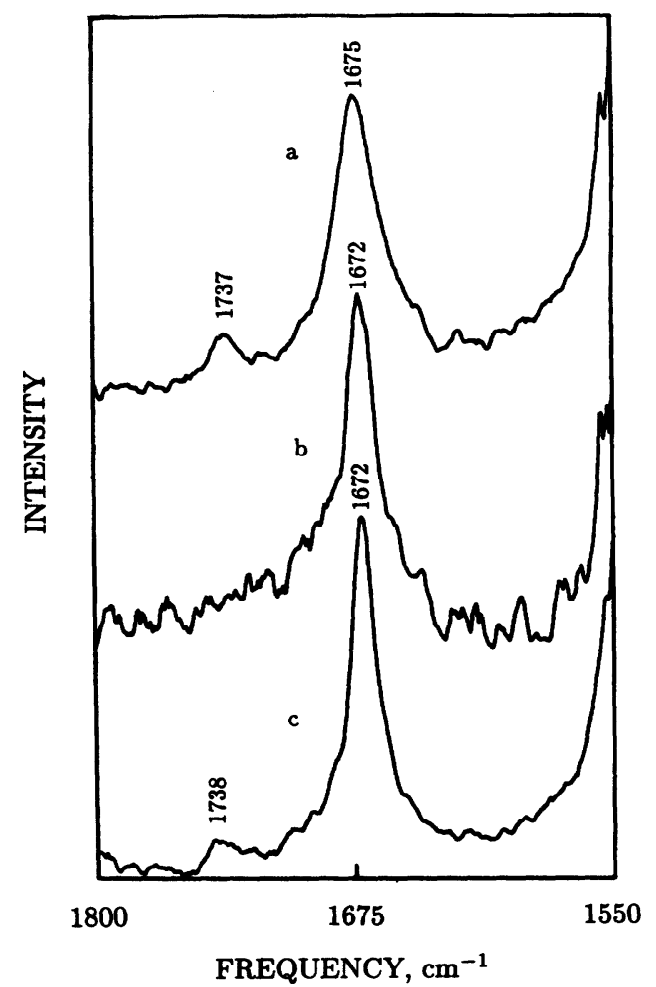

Fig. 9. Raman spectra in the $1800-1550 \mathrm{~cm}^{-1}$ region of (a) $(\mathrm{LD}-\mathrm{Val})_{4},(\mathrm{~b})(\mathrm{LD}-\mathrm{Val})_{6}$ and (c) (LD-Val) 8 in chloroform.
TABLE 3

Calculated amide I, II, III and IV frequencies for $\uparrow \downarrow \beta^{5.6}$ and $\uparrow \downarrow \boldsymbol{\beta}^{7.2}$ structures ${ }^{\mathrm{a}}$

\begin{tabular}{|c|c|c|c|c|c|c|}
\hline \multirow[t]{3}{*}{ Mode } & \multicolumn{3}{|c|}{$\uparrow \downarrow \beta^{5.6}$} & \multicolumn{3}{|c|}{$\uparrow \downarrow \beta^{7.2}$} \\
\hline & \multicolumn{3}{|c|}{ Species $^{b}$} & \multicolumn{3}{|c|}{ Species $^{b}$} \\
\hline & $\bar{A}$ & $E_{1}$ & $E_{2}$ & $\bar{A}$ & $E_{1}$ & $E_{2}$ \\
\hline \multirow[t]{4}{*}{ Amide I } & 1672 & 1675 & 1674 & 1686 & 1677 & 1675 \\
\hline & 1669 & 1669 & 1674 & 1674 & 1674 & 1674 \\
\hline & 1666 & 1666 & 1671 & 1667 & 1662 & 1671 \\
\hline & $1636^{c}$ & 1656 & 1662 & $1632^{c}$ & 1651 & 1667 \\
\hline \multirow[t]{4}{*}{ Amide II } & 1547 & 1553 & 1547 & 1556 & 1556 & 1559 \\
\hline & 1547 & 1550 & 1546 & 1554 & 1555 & 1555 \\
\hline & 1535 & 1542 & 1544 & 1537 & 1552 & 1549 \\
\hline & 1531 & 1541 & 1543 & 1537 & 1549 & 1547 \\
\hline \multirow[t]{8}{*}{ Amide III } & 1386 & 1374 & 1378 & 1316 & 1393 & 1379 \\
\hline & 1385 & 1373 & 1377 & 1314 & 1392 & 1378 \\
\hline & 1312 & 1341 & 1334 & 1296 & 1344 & 1365 \\
\hline & 1309 & 1340 & 1333 & 1294 & 1344 & 1364 \\
\hline & 1288 & 1267 & 1271 & 1246 & 1274 & 1266 \\
\hline & 1284 & 1265 & 1268 & 1244 & 1273 & 1265 \\
\hline & 1240 & 1237 & 1238 & & 1245 & 1245 \\
\hline & & 1236 & 1236 & & 1244 & 1244 \\
\hline \multirow[t]{6}{*}{ Amide V } & 725 & 720 & 719 & 680 & 684 & 637 \\
\hline & 717 & 717 & 716 & 668 & 643 & 631 \\
\hline & 714 & 707 & 708 & 658 & 634 & 626 \\
\hline & 712 & 695 & 694 & 629 & 627 & 618 \\
\hline & 692 & 656 & 637 & 625 & 617 & \\
\hline & & 640 & & 616 & & \\
\hline
\end{tabular}

a From Naik and Krimm [14]. ${ }^{b}$ Modes of $A$ and $E_{1}$ symmetry are both Raman and IR active whereas modes of $E_{2}$ symmetry are only Raman active. ${ }^{\mathbf{c}}$ Highest intensity IR mode.

the Raman spectrum and are fairly intense in the IR spectrum. These are easily detectable by $N$ deuteration. For the $\uparrow \downarrow \beta^{5.6}$ structure, the amide $V$ modes are calculated at 725-707, 695-692, 656 and $640 \mathrm{~cm}^{-1}$. The observed amide $V$ modes for the three oligopeptides (see Table 1) are consistent with the $\uparrow \downarrow \beta^{5.6}$ structure. However, it should be pointed out that the predicted frequencies for the $\uparrow \downarrow \beta^{7.2}$ structure are also comparable to the observed frequencies, but the predicted amide $\mathbf{V}$ modes for the parallel double-stranded helices $\left(\uparrow \uparrow \beta^{5.6}\right.$ and $\left.\uparrow \uparrow \beta^{7.2}\right)$ are clearly inconsistent with the observed frequencies [14].

In summary, the similarity of the observed spectra of (LD-Val) $n$ with $n=4,6$ and 8 indicates that the structures of these peptides in the crys- 
TABLE 4

Calculated amide I, II, III and V frequencies for $\beta^{4.4}$ and $\beta^{6.3}$ structures ${ }^{\text {a }}$

\begin{tabular}{|c|c|c|c|c|c|c|}
\hline \multirow[t]{3}{*}{$\overline{\text { Mode }}$} & \multicolumn{3}{|l|}{$\beta^{4.4}$} & \multicolumn{3}{|l|}{$\beta^{6.3}$} \\
\hline & \multicolumn{3}{|c|}{ Species $^{b}$} & \multicolumn{3}{|c|}{ Species $^{b}$} \\
\hline & $\bar{A}$ & $\overline{E_{1}}$ & $\overline{E_{2}}$ & $\bar{A}$ & $E_{1}$ & $E_{2}$ \\
\hline \multirow[t]{2}{*}{ Amide I } & 1648 & 1653 & 1681 & 1652 & 1654 & 1652 \\
\hline & $1631^{c}$ & 1644 & 1672 & $1643^{c}$ & 1645 & 1652 \\
\hline \multirow[t]{2}{*}{ Amide II } & 1540 & 1564 & 1543 & 1570 & 1572 & 1573 \\
\hline & 1534 & 1538 & 1538 & 1542 & 1559 & 1557 \\
\hline \multirow[t]{6}{*}{ Amide III } & 1358 & 1363 & 1359 & 1376 & 1442 & 1439 \\
\hline & 1327 & 1330 & 1328 & 1321 & 1401 & 1406 \\
\hline & 1218 & 1249 & 1218 & 1264 & 1303 & 1301 \\
\hline & 1186 & 1224 & 1187 & 1201 & 1266 & 1266 \\
\hline & 1181 & 1179 & 1181 & 1182 & 1207 & 1208 \\
\hline & & & & & 1187 & 1187 \\
\hline \multirow[t]{3}{*}{ Amide V } & 734 & 733 & 735 & 698 & 698 & 696 \\
\hline & 683 & 720 & 685 & 677 & 677 & 678 \\
\hline & & 680 & & 574 & 658 & 644 \\
\hline
\end{tabular}

a-c See Table 3.

talline state are similar. As ( $\mathrm{LD}-\mathrm{Val})_{4}$ is known to exist as a $\uparrow \downarrow \beta^{5.6}$ helix in the crystalline state, the fact that the IR and Raman spectra of these three oligopeptides are similar implies a $\uparrow \downarrow \beta^{5.6}$ structure for (LD-Val) ${ }_{6}$ and (LD-Val) $)_{8}$ in the crystalline state. The amide A, B, I, II, III and V frequencies observed in (LD-Val) $)_{8}$ represent the characteristic of a $\uparrow \downarrow \beta^{5.6}$ structure.

\section{Conformation of oligovalines in solution}

For ( $\mathrm{LD}-\mathrm{Val})_{4}$ there are no major differences in the observed frequencies, in the amide $A$ and I regions, compared with the solid-state spectra. The strongest Raman band observed at $1678 \mathrm{~cm}^{-1}$ in the solid state shifts to $1675 \mathrm{~cm}^{-1}$ in $\mathrm{CHCl}_{3}$. The strongest IR band, observed at $1644 \mathrm{~cm}^{-1}$ in the solid state, shifts to $1645 \mathrm{~cm}^{-1}$ in cyclohexane (spectrum not shown, see [24]). This difference is within the experimental uncertainty in measuring the peak positions. Amide A is observed at $\mathbf{3 2 9 5}$ $\mathrm{cm}^{-1}$ both in the solid and in cyclohexane. This clearly indicates that the structure of (LD-Val) ${ }_{4}$ in cyclohexane is essentially similar to its structure in the crystalline state. These results are in agreement with the earlier NMR and IR studies [24]. However, in chloroform it exists as a $\uparrow \downarrow \beta^{5.6}$ and a mixture of various interconverting conformers, as indicated by NMR results [24]. The present Raman spectra do not show any appreciable difference between the two solvents $\mathrm{CHCl}_{3}$ and cyclohexane. This probably means that the percentage of interconverting conformers in $\mathrm{CHCl}_{3}$ is very small compared with $\uparrow \downarrow \beta^{5.6}$ conformers.

For (LD-Val) 6 , the IR and Raman spectra in chloroform are notably different compared with the solid state. The strongest Raman band observed at $1676 \mathrm{~cm}^{-1}$ in the solid shifts down to $1672 \mathrm{~cm}^{-1}$ and a new band appears (shoulder) at ca. $1689 \mathrm{~cm}^{-1}$. The strongest IR band observed at $1640 \mathrm{~cm}^{-1}$ in the solid shifts up to $1651 \mathrm{~cm}^{-1}$ in $\mathrm{CHCl}_{3}$ (see Fig. 8). The higher frequency region of amide $\mathrm{I}$ band (ca. $1680 \mathrm{~cm}^{-1}$ ) in $\mathrm{CHCl}_{3}$ is not as asymmetric as it is in the solid state, there being only a weak shoulder near $1680 \mathrm{~cm}^{-1}$. The large upward shift observed in the amide I mode in $\mathrm{CHCl}_{3}$ indicates a different conformation of the molecule. The $1651 \mathrm{~cm}^{-1}$ band may be due to the presence of a $\beta^{4.4}$ single-helical structure in $\mathrm{CHCl}_{3}$ solution. The predicted frequencies for the $\beta^{4.4}$ and $\beta^{6.3}$ structures (see Table 4) are at ca. $1650 \mathrm{~cm}^{-1}$ in the $A$ symmetry species [14]. Comparable frequencies are not predicted for the double helical structures (see Table 3 ). This makes it possible to assign either $\beta^{4.4}$ or $\beta^{6.3}$ structure for (LD-Val) ${ }_{6}$ in $\mathrm{CHCl}_{3}$ solution. However, the $\beta^{6.3}$ structure can be ruled out based on the predicted Raman active modes. The $\beta^{6.3}$ structure has no calculated frequencies greater than $1654 \mathrm{~cm}^{-1}$ whereas $\beta^{4.4}$ has a $1672 \mathrm{~cm}^{-1}$ mode in $E_{2}$ symmetry species which matches very well the observed Raman band at $1672 \mathrm{~cm}^{-1}$. These results are in agreement with the NMR studies of Tomasic et al. [25]. They showed that the double-stranded helical species $\uparrow \downarrow \beta^{5.6}$ is predominant in fresh solutions of samples obtained from $\mathrm{CHCl}_{3}$-EtOAc. At equilibrium there are three slowly interconverting species. One is the left-handed $\uparrow \downarrow \beta^{5.6}$ species and the other two are most likely single-stranded $\beta^{4.4}$ species of opposite handedness. In the present studies the samples were probably equilibrated because of the long time involved in recording the Raman spectra and the predominant species were single helical structures. 
For (LD-Val) $)_{8}$, there are no major differences in the amide $\mathrm{A}$ and $\mathrm{I}$ modes between the solid state and $\mathrm{CHCl}_{3}$ solution. This behavior is similar to that of ( $\mathrm{LD}-\mathrm{Val})_{4}$ discussed above. The strongest Raman amide I band is observed at $1672 \mathrm{~cm}^{-1}$ in both the solid state and $\mathrm{CHCl}_{3}$. The strongest IR amide $I$ band shifts from $1640 \mathrm{~cm}^{-1}$ in the solid state to $1645 \mathrm{~cm}^{-1}$ in $\mathrm{CHCl}_{3}$ solution. The amide A band is observed at $3280 \mathrm{~cm}^{-1}$ in both solid and solution states. NMR studies [26] of this peptide in $\mathrm{CHCl}_{3}$ have suggested the presence of $\beta^{4.4}$ helices. The present spectroscopic studies indicate that the conformation is similar to its conformation in the solid state. A $5 \mathrm{~cm}^{-1}$ shift in amide $\mathrm{I}$ frequency in $\mathrm{CHCl}_{3}$ solution may indicate that there is some conformational change in $\mathrm{CHCl}_{3}$ solution. However, this change is not as large as that observed in (LD-Val) 6 . However, as the frequency shift is consistent with the predicted modes for the $\beta^{4.4}$ structure, it is possible that there is a mixture of conformers in solution.

\section{Conclusions}

From IR and Raman spectroscopic measurements, in conjunction with normal-mode analysis, it has been able to assign the structures for (LDVal) $n$ with $n=4,6$ and 8 in solid and solution states. The results show that these LD-oligopeptides adopt different structures depending on the environment.

The results show that all three oligopeptides exist in the $\uparrow \downarrow \beta^{5.6}$ structure in the crystalline state. This is the structure in which the uncomplexed gramicidin A exists in the crystalline state. In solution these peptides exist in a mixture of conformations: (LD-Val) 4 as $\uparrow \downarrow \beta^{5.6}$ together with some $\beta^{4.4}$, (LD-Val) $)_{6}$ mainly as $\beta^{4.4}$ and (LD-Val) 8 mainly as $\uparrow \downarrow \beta^{5.6}$ mixed with some $\beta^{4.4}$. It is interesting that gramicidin $A$ has a $\beta^{6.3}$ structure in liposome suspension in water [16]. However, gramicidin $\mathrm{A}$ has not been found with a $\beta^{4.4}$ structure either in the crystalline state or in solution.

The author is grateful to Dr. S. Krimm for providing the use of his spectroscopy laboratory,
Dr. G.P. Lorenzi for providing the samples used in this work and Dr. J. Bandekar for useful discussions. The author is indebted to the Horace H. Rackham School of Graduate Studies for faculty fellowship.

\section{REFERENCES}

1 D.W. Urry, Proc. Natl. Acad. Sci. U.S.A., 68 (1971) 672.

2 B. Di Blasio, E. Benedetti, V. Povone, C. Pedone and G.P. Lorenzi, Biopolymers, 28 (1989) 193.

3 B. Di Blasio, E. Benedetti, V. Povone, C. Pedone, C. Gerber and G.P. Lorenzi, Biopolymers, 28 (1989) 203.

4 B.V.V. Prasad and R. Chandrasekaran, Int. J. Pept. Protein Res., 10 (1977) 129.

5 W.R. Veatch, E.T. Fossel and E.R. Blout, Biochemistry, 13 (1974) 5249.

6 G.P. Lorenzi, C. Gerber and H. Jäckle, Macromolecules, 18 (1985) 154.

7 G.P. Lorenzi and L. Tomasic, Macromol. Chem., 189 (1988) 207.

8 E. Fenude, L. Tomasic and G.P. Lorenzi, Biopolymers, 28 (1989) 185.

9 F.T. Hesselink and H.A. Scheraga, Macromolecules, 5 (1972) 455.

10 B. Lotz, F. Colonna-Cesari, F. Heitz and G. Spach, J. Mol. Biol., 106 (1976) 915.

11 F. Colonna-Cesari, S. Premilat, F. Heitz, G. Spach and B. Lotz, Macromolecules, 10 (1977) 128.

12 P.C. Jordan, J. Phys. Chem., 91 (1987) 6582.

13 S. Krimm and J. Bandekar, Adv. Protein Chem., 38 (1986) 181.

14 V.M. Naik and S. Krimm, Biophys. J., 49 (1986) 1131.

15 V.M. Naik and S. Krimm, Biochem. Biophys. Res. Commun., 125 (1984) 919.

16 V.M. Naik and S. Krimm, Biophys. J., 49 (1986) 1147.

17 B.A. Wallace, Biophys. J., 49 (1986) 295.

18 B.A. Wallace and K. Ravikumar, Science, 241 (1988) 182.

19 D.A. Langs, Science, 241 (1988) 188.

20 J.L. Koenig and P.L. Sutton, Biopolymers, 10 (1971) 89.

21 L. Simons, G. Bergström, G. Blomfelt, S. Forss, H. Stenbäck and G. Wansen, Commentat. Phys.-Math., Soc. Sci. Fenn., 42 (1972) 125.

22 B.G. Frushour, P.C. Painter and J.L. Koenig, J. Macromol. Sci. Rev. Macromol. Chem., C15 (1976) 29.

23 W.O. George, T.E. Houston and W.C. Harris, Spectrochim. Acta, 30 (1974) 1035.

24 G.P. Lorenzi, H. Jäckle, L. Tomasic, V. Rizzo and C. Pedone, J. Am. Chem. Soc., 104 (1982) 1728.

25 L. Tomasic, A. Stefani and G.P. Lorenzi, Helv. Chim. Acta, 63 (1980) 2000.

26 G.P. Lorenzi, H. Jäckle, L. Tomasic and C. Pedone, Biopolymers, 22 (1983) 157. 